\title{
EVALUATION OF ANTIBACTERIAL EFFECT OF DIODE LASER 980 NM, ENDOVAC AND PASSIVE ULTRASONIC IRRIGATION DURING FINAL IRRIGATION
}

\author{
Kariem Mostafa Elbatouty* and Mona Saad Nour**
}

\begin{abstract}
Aim: The purpose of this study is to evaluate the antibacterial effect of Diode laser $980 \mathrm{~nm}$, EndoVac and passive ultrasonic irrigation ex vivo.

Methods: One hundred and five maxillary central incisors were standardized to $15 \mathrm{~mm}$ in length. All samples were prepared using Protaper Universal rotary nickel titanium system till size \# F4 then contaminated with E. faecalis. The irrigation protocol used was $2.5 \%$ sodium hypochlorite followed by $17 \%$ EDTA. Samples were randomly divided into 5 groups $(n=20)$ according to the irrigant activation method. LAI group, Diode laser 980nm. API group, EndoVac system. PUI group, passive ultrasonic activation. The positive control group, in which the irrigating solution was not activated and the negative control group in which the samples were not subjected to irrigation or activation. Residual bacteria were collected with sterile paper point, plated onto BHI media and incubated $\left(37{ }^{\circ} \mathrm{C}, 48 \mathrm{~h}\right)$ to determine the colony-forming units (CFU mL-1). Data were analyzed using one-way ANOVA followed by performance of Tukey post hoc tests. Significance was set at p $<0.05$. Scanning electron microscopy was used to investigate the changes in biofilm.
\end{abstract}

Results: There was a statistically significant reduction in the mean numbers of colony-forming units among all groups. However, none of the activation methods was able to kill E. faecalis biofilm completely. The LAI group behaved most effectively among all groups.

Conclusion: The adjunctive use of $980 \mathrm{~nm}$ laser is an effective method for bacterial reduction after chemo-mechanical instrumentation of the root canal.

KEYWORDS: Diode laser, EndoVac, Passive ultrasonic activation, antibacterial.

\section{INTRODUCTION}

Reduction of bacteria population in the root canal system is an imperative step in attaining a successful outcome of root canal treatment ${ }^{(1)}$. Usually this can be accomplished after mechanical instrumentation with adequate irrigation. Unfortunately, culture

* Assistant Professor of Endodontics, Department of Endodontics, Faculty of Dentistry, Ain Shams University.

** Lecturer of Medical Microbiology and Immunology Department of Medical Microbiology and Immunology Faculty of Medicine, Ain Shams University. 
techniques have shown that instrumentation and irrigation alone eliminate $50-70 \%$ of root canals bacteria ${ }^{(2)}$. The remaining bacterial population is attributed to the presence of many areas in the root canal system that remained untouched after mechanical preparation regardless of the technique used ${ }^{(3)}$. The residual bacteria are usually located in isthmuses, lateral canals and apical ramifications inaccessible to instrumentation and conventional irrigation $^{(4)}$.

Enterococcus faecalis became the model organism to evaluate the antibacterial activity of different irrigants or medicaments used in endodontics because it is the most commonly isolated bacteria from root canals involved in persistent infections ${ }^{(5,6)}$. E. faecalis presents a high antimicrobial resistance and ability to adapt to environmental changes ${ }^{(7,8,9)}$. Its biofilm mode of growth and its persistence in harsh environmental conditions existing in the root canal favor its growth as a biofilm ${ }^{(10)}$. It is well known from literature that bacterial resistance to host immune response and antimicrobial agents is dramadaticly increased when the bacteria grow in a biofilm ${ }^{(11)}$. Accordingly, it is necessary to establish new control procedures against infected root canal-associated biofilms. The combinations of disinfecting solutions and irrigation devices became a smart way to approach this problem.

Traditionally the irrigant is still delivered using a disposable plastic syringe ${ }^{(12)}$. Due to the limitations of conventional irrigation ${ }^{(13,14)}$, several activation techniques have been introduced during the last few decades to enhance the penetration of irrigants and optimize its antibacterial effect in the root canal. Among these activation techniques are the passive ultrasonic activated irrigation, apical negative pressure irrigation (EndoVac system) and laser activated irrigation.

Passive ultrasonic irrigation (PUI) utilizes ultrasonic during root canal treatment ${ }^{(15)}$ applying an ultrasonically activated file ${ }^{(16)}$ or smooth wire ${ }^{(17)}$ within the root canal space following the completion of canal preparation. The term 'passive' was used to emphasize that the file is used in a 'non cutting' manner ${ }^{(18)}$.

The EndoVac system is based on negative pressure that creates a flow strong enough to flush out debris but preventing the risk of injury due to overflow of the irrigant to periapical tissues ${ }^{(19)}$. The system consists of a master delivery tip, a macrocannula and a microcannula, which allow the delivery and evacuation of the irrigating solution concomitantly ${ }^{(20)}$.

Lately, a provocative way to manage pathogens is by using lasers. Laser technology represents an evolution of medical techniques and an indispensable daily support to the traditional dental practice. The antimicrobial effects of various lasers in the root canal have been studied in vitro, and most reports have indicated that laser irradiation is useful for bacterial suppression (21,22) because it can energize or create intense streaming within an endodontic irrigant (23). Literature reports, laser energy may increase the reaction kinetics of some irrigants for example sodium hypochlorite $(\mathrm{NaOCl}){ }^{(24)}$. In addition laser can enhance smear layer removal ${ }^{(25,26)}$ and can increase debris removal from the apical third of the root canal system ${ }^{(27)}$. Little is known about eliminating biofilms from the root canal system using laser technology.

The aim of this study was to evaluate the antibacterial effect during or following final irrigation comparing laser disinfection to two currently used activation techniques: negative apical pressure (EndoVac system) and passive ultrasonic activation. The null hypothesis indicates that there is no difference between the antibacterial effects of the three activation techniques under investigation.

\section{MATERIALS AND METHODS}

\section{Sample Preparation}

One hundred and five human caries-free maxillary central incisors with mature apices 
extracted for periodontal reasons were selected for this study. All teeth were collected from 40-55 year old patients attending the outpatient clinic at the Oral Surgery Department, Faculty of Dentistry, Ain Shams University, Cairo, Egypt and stored in $0.9 \%$ physiological saline. The teeth were used in the study after obtaining institutional review board approval that was based on the regulations of the Ethical Committee of the Faculty of Dentistry, Ain Shams University.

The crown was removed to obtain a standard length of $15 \mathrm{~mm}$ by using a safe sided diamond disc (NTI diamond disc, Axis Dental, USA) mounted on a high-speed contra angle with water coolant. All canals were cleaned and shaped by rotary nickeltitanium ProTaper instruments (Dentsply Maillefer, Ballaigues, Switzerland) until size \# F4.

The root canals were irrigated with $3 \mathrm{ml}$ of $2.5 \%$ $\mathrm{NaOCl}$ after each instrument. Final irrigation was performed with $3 \mathrm{ml}$ of $2.5 \% \mathrm{NaOCl}$ followed by $3 \mathrm{ml}$ 17\% EDTA solution for 1 minute then rinsed with saline and dried using sterile paper points. The roots were then waterproofed externally using cyanoacrylate. Finally, the roots were steam autoclaved (MELAG, Medizintechnik Geneststraße, Berlin) at $134{ }^{\circ} \mathrm{C}$ for 15 minutes and kept at $40^{\circ} \mathrm{C}$.

\section{Cultivation of E. Faecalis Biofilm}

A clinical reference isolate of Enterococcus faecalis from the microbiology laboratory (Microbiology Department, Faculty of Medicine, Ain Shams University, Egypt) was cultured on brain-heart infusion agar (BHI) (Land Bridge Technology Co, Ltd, Beijing, China) and incubated anaerobically at $37^{\circ} \mathrm{C}$ for $24 \mathrm{hr}$. A single colony was collected and suspended in sterile BHI broth at $37^{\circ} \mathrm{C}$. The teeth were placed into1.5 $\mathrm{ml}$ Eppendorf tubes with $1-\mathrm{ml}$ BHI broth containing $10^{8}$ colony forming units $(\mathrm{CFU}) / \mathrm{ml}$ E. faecalis and then incubated anaerobically at $37^{\circ} \mathrm{C}$ for 3 weeks. The sterile BHI broth was refreshed every day to ensure bacteria viability. Five specimens were randomly selected and examined by scanning electron microscopy (SEM) (S-4800; Hitachi, Tokyo, Japan) to ensure the presence of E. faecalis biofilm ${ }^{(28)}$ (Figure1).

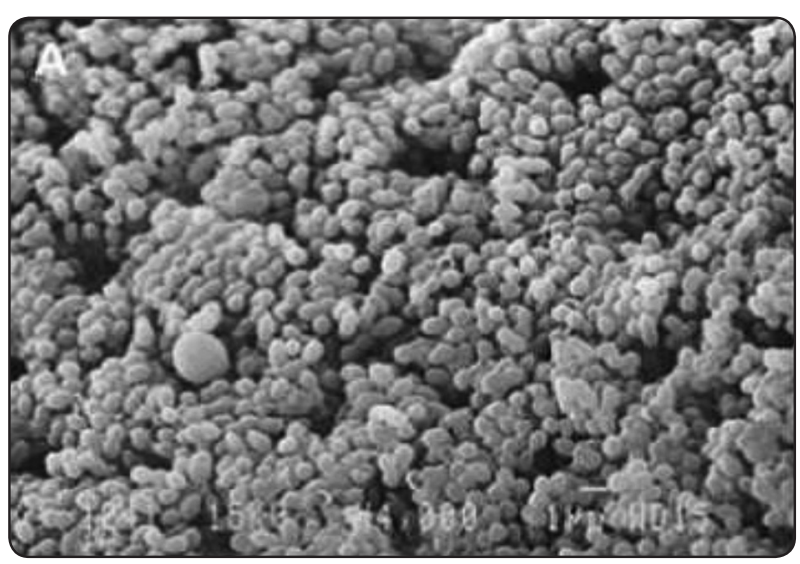

Fig. (1) Showing a 30-days-old biofilm with an increase in the number and density of the bacterial micro colonies to a remarkable thickness that is almost covering the entire dentinal surface

\section{Classification of Samples}

Samples $(\mathrm{n}=100)$ were randomly divided into 5 groups $(n=20)$ according to the activation protocol. LAI group, the irrigating solution was activated using Diode laser 980nm (doctor smile, LAMBDA Spa, Brendola, Italy). API group, the irrigating solution was activated using Endovac system (Discus Dental, Culver City, CA). PUI group, the irrigating solution was activated using ultrasonic file (Obtura Spartan, Earth City, MO, USA). The positive control group, the irrigating solution was not activated and the negative control group, the samples were not subjected to irrigation or activation.

\section{Final irrigation}

The irrigation procedure was divided into 3 sessions. In the first session, the irrigant used was $2.5 \mathrm{ml}$ of $17 \%$ EDTA followed by the second session where the irrigant used was $2.5 \mathrm{ml}$ of $2.5 \% \mathrm{NaOCl}$. Finally the canal was flushed with $5 \mathrm{ml}$ of sterile saline in the third session. The total irrigation time was standardized as $2 \mathrm{~min}$ for each session. The 
irrigants were delivered using 30-gauge Max-iprobe needle to the working length in LAI and PUI groups.

\section{LAI group:}

Intracanal irradiation was performed using a high power $980 \mathrm{~nm}$ diode laser (doctor smile, LAMBDA Spa, Brendola, Italy) following the manufacturer recommendation. The laser device was set at a power of $1.25 \mathrm{~W}$ (peak $2.50 \mathrm{~W}$ ) pulsed mode with $50 \%$ duty cycle and $50 \mathrm{~Hz}$ frequencies. The diode fiber $(200 \mu \mathrm{m}$ fibreoptic tip) was placed $1 \mathrm{~mm}$ short of the apex and recessed in helicoidal movements at a speed of approximately $2 \mathrm{~mm} / \mathrm{sec}$ for 5 seconds, and repeated 8 times at intervals of 10 seconds with a total time equal to 110 seconds per each session.

\section{API group:}

Following the previously mentioned three sessions of irrigation, the irrigant was activated using the EndoVac system (Discus Dental, Culver City, CA) following the manufacturer recommendation. In each session, the EndoVac delivery/evacuation tip was placed above orifice to constantly deliver and evacuate the irrigant and two micro-irrigation cycles of 60 seconds were followed with a total time equal to $2 \mathrm{~min}$. In each micro-irrigation cycle, the canal was maintained full of irrigant while the micro-cannula was placed at working length for
10 seconds. The micro-cannula was then positioned $2 \mathrm{~mm}$ from working length for 10 seconds and then moved back to working length for 10 seconds. After this 30 seconds micro-cycle, the micro-cannula was withdrawn from the canal and the canal was filled with irrigant and left undisturbed for 30 seconds.

\section{PUI group:}

The irrigant was activated for 2 minutes in this group using \#15 ultrasonic file (Obtura Spartan, Earth City, MO, USA). The power setting of the ultrasonic unit (Piezon Master 400; Electro Medical Systems SA, Nyon, Switzerland) was set at the $1 / 4$ of the scale ${ }^{(18)}$. In the Positive control group, the three sessions of irrigation were performed without any method of activation. In the Negative control group; the samples were left undisturbed without any irrigation nor activation.

\section{Assessment of Antibacterial Activity}

The canals were filled with sterile $0.85 \%$ normal saline solution. The H file (size \# 40) was introduced in the canal and churned for 1 minute then two sterile paper points (size \# 40) were inserted into the canal to collect the bacteria for 1 minute. The paper points were transferred into $1 \mathrm{ml}$ normal saline, and the process was repeated 3 times. All samples were vortexed for twenty seconds and 10-fold dilutions were prepared in saline. Aliquots of $0.1 \mathrm{ml}$ were
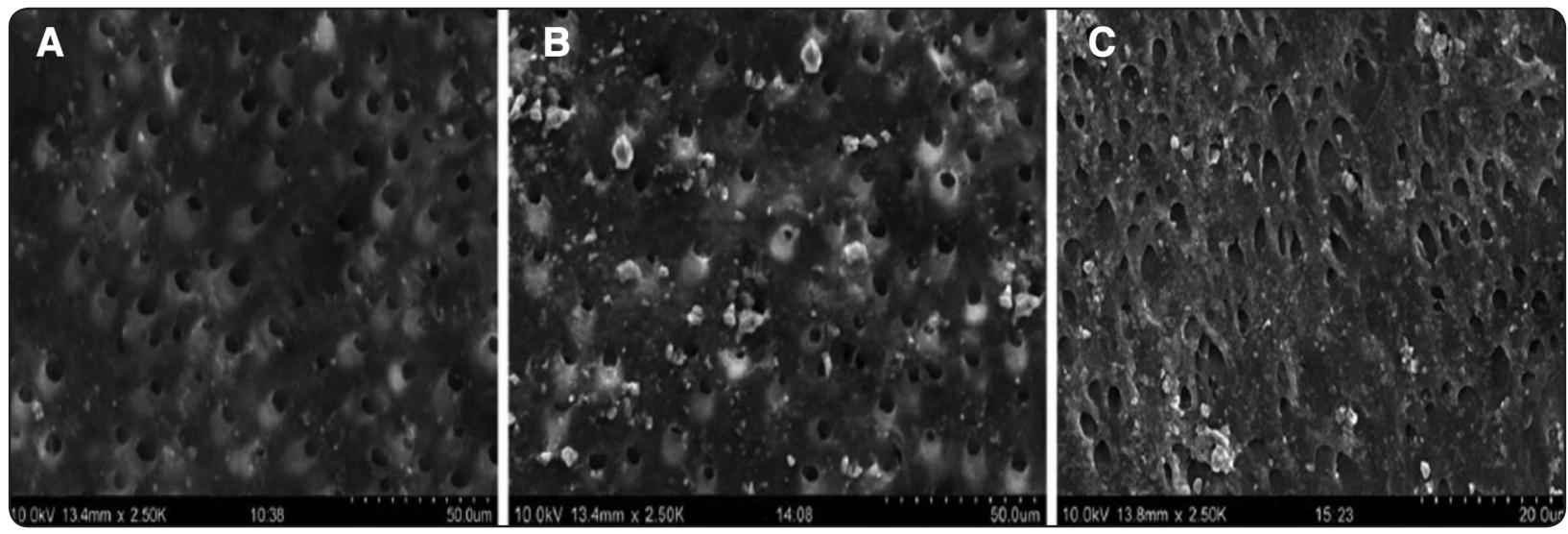

Fig. (2) SEM micrographs showing selected samples representing the different irrigant activation techniques. (A) LAI group (B) API group (C) PUI group 
spread plated onto BHI agar plates, incubated at $37^{\circ} \mathrm{C}$ for 48 hours, and colony-forming units (CFU) per $1 \mathrm{ml}$ were enumerated ${ }^{(29,30,31)}$. Five specimens were randomly selected and examined by SEM (S4800; Hitachi, Tokyo, Japan) to observe the changes in the E. faecalis biofilm ${ }^{(28)}$ (Figure2).

\section{Statistical analysis}

The means and standard deviations of (CFU)/ $\mathrm{ml}$ E. faecalis were calculated. Statistical analysis was performed using the SPSS program for Windows 10.0 (spss Inc., Chicago, IL, USA). It was determined by using one-way analysis of variance ANOVA followed by performance of Tukey post hoc tests. Significance was set at $\mathrm{p}<0.05$.

\section{RESULTS}

Results shown in table 1 revealed that all groups acquired a (CFU)/mLE. faecalis reduction compared with the negative control group (108 CFU/ml). However, none of the activation methods or the conventional irrigation was able to kill $E$. faecalis biofilm completely. The LAI group behaved most effectively among all groups.

TABLE (1) Colony-forming units $(\mathrm{CFU} / \mathrm{mL})$ E. faecalis (Mean $\pm \mathrm{SD})$ for all groups.

\begin{tabular}{|c|c|c|c|c|c|}
\hline Groups & LAI & API & PUI & Positive control & P-value \\
\hline Mean \pm SD & $0.54^{\mathrm{a}} \pm 0.11$ & $8.0^{\mathrm{b}} \pm 1.16$ & $4.38^{\mathrm{c}} \pm 0.68$ & $10.27^{\mathrm{d}} \pm 1.49$ & $<0.0001^{*}$ \\
\hline
\end{tabular}

*: Significant at $P \leq 0.05$, Different small letters in the same row indicate significant differences between groups at $P \leq 0.05$.

\section{DISCUSSION}

The success of root canal treatment is related to the efficiency of cleaning and shaping process in disinfection of the root canal system. However, to obtain a thoroughly bacteria-free cleaned and shaped root canal is still a questionable request that is unlikely to be found ${ }^{(32)}$. The use of laser technology for root canal disinfection provides an opportunity to reduce the problems resulting from the inability of instruments and irrigants to access difficult areas of root canal.

E. faecalis was selected as the test organism in this study as it is the bacterial species most frequently associated with persistent endodontic infections ${ }^{(33,34)}$, in addition to its ability to grow in biofilm. Furthermore, 3-weeks old E. faecalis biofilms were selected for this study due to its higher resistance than the younger aged biofilms ${ }^{(35)}$, making its elimination more difficult ${ }^{(36)}$.
In literature many studies tried to create an experimental model mimicking the in vivo clinical situation. For example, biofilms grown in wells ${ }^{(37)}$, on membrane filters ${ }^{(38)}$ and on dentin samples ${ }^{(39)}$. However, the bacterial colonization structure on dentinal collagen comprises more natural biological representation because of dentinal tubules, which contain a considerable amount of un-mineralized collagen ${ }^{(38)}$, and type I collagen serves as an adhesion substrate to oral streptococci ${ }^{(39)}$.

The results of the current study (Table 1) showed that null hypothesis should be rejected because of the highly significant difference found between all groups $(\mathrm{P}<0.0001)$. The laser group showed the lowest residual bacterial load. This can be attributed to the laser energy that tends to accelerate the movement of irrigating solution pushing it into complicated canal anatomy. According to literature laser light reaches over $1 \mathrm{~mm}$ deep into the dentin ${ }^{[40]}$. Absorption of laser energy in the target 
tissue leads to generation of temperature rise. Thus the activated rinsing solution provokes dissociation of covalent bonds in cell proteins ${ }^{[41]}$.

Another possible reason that was previously described by Wilson ${ }^{(42)}$ is that the mechanism of laser light on planktonic bacteria is due to photochemical alterations inside living cells. Thus, the effects of various dental lasers on biofilms would be different according to water content, the components of the extracellular matrix, cell density, and absorption properties. The anti-biofilm actions of the laser might be due to absorption of water in biofilms, and small numbers of residual viable cells might undergo thermal necrosis.

However laser did not render the root canal totally free from bacteria. This is may be due to the inability of laser beam to spread laterally towards the root canal wall and this is due to the high degree of focus of the laser beam limiting its effect to the main canal without affecting the deeper layers of dentinal tubules. In addition to the resistance of $E$. faecalis to laser irradiation because of its gram-specific cell wall structure ${ }^{(43)}$ and/or the resistance of starved E. faecalis cells to different conditions ${ }^{(44)}$. Another reason is the ability of $E$. faecalis to migrate deeply into dentinal tubules, which may protect them from proper irradiation ${ }^{(45)}$.

In a study on extracted teeth, Diode laser with $810 \mathrm{~nm}$ was used to reduce intra canal bacteria. Results showed that this laser is effective for eliminating Enterococcus Faecalis ${ }^{(46)}$. Gutknecht et al demonstrated that Diode laser with $980 \mathrm{~nm}$ wavelength can eliminate bacteria which have penetrated to a depth of 500 microns in dentin ${ }^{(47)}$. De Souza et al demonstrated that the use of Diode laser $830 \mathrm{~nm}$ after biomechanical preparation leads to an increased amount of canal disinfection ${ }^{(48)}$. In addition, Neelakantan et al ${ }^{(49)}$ found that Diode laser $940 \mathrm{~nm}$ was superior to ultrasonics in root canal disinfection. Also Ordinola-Zapata et al ${ }^{(50)}$ found that Er:YAG laser with a wavelength of 2940 $\mathrm{nm}$ provides superior bacterial reduction than both sonic and ultrasonic activation methods.

According to Fransson et al. ${ }^{(51)}$ laser treatment should not be used; in their systematic review they found no positive effect of laser treatment as an adjunct to chemo-mechanical treatment of infected root canals. In addition, Omid et al ${ }^{(52)}$ found that PUI in combination to $\mathrm{NaOCl}$ provides significantly better reduction of bacterial load and destruction of microbial biofilm than Diode laser $650 \mathrm{~nm}$.

Brito et al. (53) demonstrated no differences between the EndoVac and other irrigation techniques and this was in agreement with our result. On the other hand, several studies reported that the EndoVac system offered better cleaning of the root canal than conventional or ultrasonic irrigation ${ }^{(54)}$. Conflicting data on the antimicrobial efficacy of the EndoVac system may be explained by methodological variances amongst studies such as the volume and type of the irrigant.

Our results showed that PUI significantly decreases the microbial colonies and this was in agreement with Gründling et al ${ }^{(55)}$ who concluded that PUI could be an aid in cleaning the root canal. Ultra-sonic irrigation improves the effects of $\mathrm{NaOCl}$ and EDTA by acoustic streaming. The solution can reach all parts of the canal even the non instrumented one. Also, this is directly related to the previous confirmation that irrigant velocity on the root canal wall is an important fluid mechanic parameter, and shear stress on the canal wall influences the mechanical detachment of debris, isolated microbes and biofilm ${ }^{(56)}$.

In this study, single straight root canals were selected to facilitate comparison of the bactericidal effect among different activation techniques under standard conditions. However, in clinical practice, there are many teeth with curved root canals. In such a case the bactericidal effect of laser systems might be reduced if the optical fiber cannot be inserted in the canal to the necessary length. Therefore, evaluation of the bactericidal effect of these systems in curved root canals will be performed in 
our future investigations. Also the efficacy of these activation techniques should be further determined on multispecies biofilm. In order to further confirm these results, the investigation of the antibacterial effect of laser systems under in vivo conditions, is necessary.

In fact, in vivo the presence of organic material (e.g.inflammatory exudates, pulpal tissue fragments, dentinal collagen and bacterial debris) within root canals may hinder the penetration of the laser beam and significantly weakens its antibacterial action. The count of bacteria in biofilm in the current study was achieved by CFU protocol after detaching them from the surface on which they adhere by vortexing or sonication. However, these procedures often do not obtain homogeneous cell suspensions, thus introducing a relevant bias in the results ${ }^{(57)}$. In the present study, microorganisms were collected with sterile paper points from the root canal system. This sampling method has limitations because the paper points are only able to detect planktonic bacteria. Moreover, the paper points cannot access irregularities and other regions of the root canal system. Consequently, this approach might fail to harvest viable bacteria in biofilms and in some areas of the root canal system ${ }^{(58)}$. Thus, we accomplished the bacterial sampling by instrumenting the canal wall with sterile \#40 to remove dentine, permitting for a more predictable sampling.

Additionally, some cells of E. faecalis in biofilms can enter a stationary phase, which makes them undetectable with conventional culture methods ${ }^{(9)}$. Thus, the data obtained from CFU counts must be interpreted with caution.

\section{CONCLUSION}

Based on the outcomes in the present study, it can be concluded that the diode laser $980 \mathrm{~nm}$ tested in the present study can provide an additional aid in root canal disinfection. This in addition to the fact that the reduction of bacterial load through conventional chemo-mechanical treatment of root canal system is sufficient, in most cases, to obtain a favorable prognosis, the possibility of increasing the antibacterial effect through the use of laser systems must be given serious consideration.

\section{REFERENCES}

1. Christo JE, Zilm PS, Sullivan T, Cathro PR. Efficacy of low concentrations of sodium hypochlorite and low powered Er, Cr:YSGG laser activated irrigation against an Enterococcus faecalis biofilm. Int Endod J 2015; 279-286.

2. Shuping GB, Ørstavik D, Sigurdsson A, Trope M. Reduction of intracanal bacteria using nickel-titanium rotary instrumentation and various medications. J Endod 2000;26:751-755.

3. Peters OA, Laib A, Gohring TN, Barbakow F. Changes in root canal geometry after preparation assessed by highresolution computed tomography. J Endod 2001;27:1-6.

4. Vera J, Siqueira JF Jr, Ricucci D, Loghin S, Fernadez N, Flores B, Cruz AG. One- versus two-visit endodontic treatment of teeth with apical periodontitis: a histobacteriologic study. J Endod 2012;38:1040-1052.

5. Chavez de Paz LE. Redefining the persistent infection in root canals: possible role of biofilm communities. J Endod 2007;33:652-662.

6. Stuart CH, Schwartz SA, Beeson TJ, et al. Enterococcus faecalis: its role in root canal treatment failure and current concepts in retreatment. J Endod 2006;32:93-98.

7. Dahlén G, Samuelsson W,Molander A, Reit C.Identification and antimicrobial susceptibility of enterococci isolated from the root canal. Oral Microbiol Immunol 2000; 15:309-312.

8. Eddy RS, Joyce AP, Roberts S, Buxton TB, Liewehr F. An in vitro evaluation of the antibacterial efficacy of chlorine dioxide on E. faecalis in bovine incisors. J Endod 2005;31:672-675.

9. Liu H, Wei X, Ling J, Wang W, Huang X. Biofilm formation capability of Enterococcus faecalis cells in starvation phase and its Susceptibility to Sodium Hypochlorite. J Endod 2010;36:630-635.

10. Tronstad L, Sunde PT. The evolving new understanding of endodontic infections. Endodontic Topics 2003;6:57-77.

11. Mah TF, O'Toole GA. Mechanisms of biofilm resistance to antimicrobial agents. Trends Microbiol 2001;9:34 -39. 
12. Haapasalo $\mathbf{M}$, Shen $\mathrm{Y}$, Qian W, Gao Y. Irrigation in endodontics. Dent Clin North Am 2010;54:291-312.

13. Zehnder M. Root canal irrigants. J Endod 2006, 32:389-398.

14. Paque F, Laib A, Gautschi H, Zehnder M. Hard-tissue debris accumulation analysis by high-resolution computed tomography scans. J Endod 2009,35:1044-1047.

15. Gutarts R, Nusstein J, Reader A, Beck M. In vivo debridement efficacy of ultrasonic irrigation following hand or rotary instrumentation in human mandibular molars. J Endod 2005;31:166-170.

16. Weller N, Brady JM, Bernier WE. Efficacy of ultrasonic cleaning. J Endod 1980;6:740-744.

17. Van der Sluis LW, Shemesh H, Wu MK, Wesselink PR. An evaluation of the influence of passive ultrasonic irrigation on the seal of root canal fillings. Int Endod J 2007;40:356361.

18. Bhuva B, Patel S, Wilson R, Niazi S, Beighton D, Mannocci F. The effectiveness of passive ultrasonic irrigation on intraradicular Enterococcus faecalis biofilms in extracted single-rooted human teeth. Int Endod J 2010;43:241-250.

19. Desai P, Himel V. Comparative safety of various intracanal irrigation systems. J Endod 2009;35:545-549.

20. Gregorio C, Estevez R, Cisneros R, Paranjipe A, Cohenca N. Efficacy of different irrigation and activation systems on the penetration of sodium hypochlorite into simulated lateral canals and up to working length: an in vitro study. J Endod 2010;36:1216-1221.

21. Wang QQ, Zhang CF, Yin XZ. Evaluation of the bactericidal effect of Er,Cr:YSGG, and Nd:YAG lasers in experimentally infected root canals. J Endod 2007; 33:830 -832.

22. Folwaczny M, Mehl A, Jordan C, Hickel R. Antibacterial effects of pulsed Nd:YAG laser radiation at different energy settings in root canals. J Endod 2002;28:24-29.

23. De Groot SD, Verhaagen B, Versluis M, Wu MK, Wesselink PR, Van Der Sluis LWM. Laser-activated irrigation within root canals: cleaning efficacy and flow visualization. Int Endod J 2009;42:1077-1083.

24. Macedo RG, Wesselink PR, Zaccheo F, Fanali D, van der Sluis LWM. Reaction rate of $\mathrm{NaOCl}$ in contact with bovine dentine: effect of activation, exposure time, concentration and pH. Int Endod J 2010;43:1108-1115.

25. George R, Meyers IA, Walsh LJ. Laser activation of endodontic irrigants with improved conical laser fiber tips for removing smear layer in the apical third of the root canal. J Endod 2008;34:1524-1527.
26. DiVito E, Peters O, Olivi G. Effectiveness of the erbium:YAG laser and new design radial and stripped tips in removing the smear layer after root canal instrumentation. Lasers Med Sci 2012;27:273-280.

27. De Moor RJ, Blanken J, Meire M, Verdaasdonk R. Laser induced explosive vapor and cavitation resulting in effective irrigation of the root canal. Part 2: evaluation of the efficacy. Lasers Surgery Med2009;41:520-523.

28. Li Y, Sun K, Ye G, Liang Y, Pan H, Wang G, Zhao Y, Pan J, Zjang J, Fang J. Evaluation of cold plasma treatment and safety in disinfecting 3-week root canal Enterococcus faecalis biofilm in vitro. J Endod 2015;41:1325-1330.

29. Seal Gj, Ng Yl, Spratt D, Bhatti M, Gulabivala K. An in vitro comparison of the bacterial efficacy of lethal photosensitization or sodium hypochlorite irrigation on Streptococcus intermedius biofilms in root canals. Int Endod J 2002;35:268-274.

30. Souza LC, Brito PR, de Oliveira JC, Alves FR, Moreira EJ, Sampaio-Filho HR, Rocas IN, Siqueira JF Jr. Photodynamic therapy with two different photosensitizers as a supplement to instrumentation /irrigation procedures in promoting intracanal reduction of Enterococcus faecalis. J Endod 2010;36:292-296.

31. Miranda RG, Santos EB, Souto RM, Gusman H, Colombo AP. Ex vivo antimicrobial efficacy of the EndoVac system plus photodynamic therapy associated with calcium hydroxide against intracanal Enterococcus faecalis. Int Endod J 2013;46:499-505.

32. Nair PNR, Henry S, Cano V, Vera J. Microbial status of apical root canal system of human mandibular first molars with primary apical periodontitis after 'one-visit' endodontic treatment. Oral Surg Oral Med Oral Pathol Oral Radiol Endod 2005; 99: 231-252.

33. Wang Z, Shen Y, Haapasalo M. Effectiveness of endodontic disinfecting solutions against young and old Enterococcus faecalis biofilms in dentin canals. J Endod 2012; 38: 1376 1379.

34. Wilson M. Susceptibility of oral bacterial biofilms to antimicrobial agents. J Med Microbiol 1996;44:79-87.

35. Stojicic S, Shen Y, Haapasalo M. Effect of the source of biofilm bacteria, level of biofilm maturation, and type of disinfecting agent on the susceptibility of biofilm bacteria to antibacterial agents. J Endod 2013;39:473-477.

36. Lee Y, Han SH, Hong SH, et al. Antimicrobial efficacy of a polymeric chlorhexidine release device using in vitro 
model of Enterococcus faecalis dentinal tubule infection. J Endod 2008;34:855-858.

37. Dunavant TR, Regan JD, Glickman GN, Solomon ES, Honeyman AL. Comparative evaluation of endodontic irrigants against Enterococcus faecalis biofilms. J Endod 2006; 32:527-531

38. Spratt DA, Pratten J, Wilson M, Gulabivala K. An in vitro evaluation of the antimicrobial efficacy of irrigants on biofilms of root canal isolates. Int Endod J 2001;34:300307.

39. Duggan JM, Sedgley CM. Biofilm Formation of Oral and Endodontic Enterococcus faecalis. J Endod 2007;33:815818.

40. Schoop U, Kluger W, Moritz A, Nedjelik N, Georgopoulos A, Sperr W. Bactericidal effect of different laser systems in the deep layers of dentin. Lasers Surg Med. 2004; 35 : 111-116.

41. Moshonov J, Stabholz A, Leopold Y, Rosenberg I, Stabholz A. Lasers in dentistry. Part B - interaction with biological tissues and the effect on the soft tissues of the oral cavity, the hard tissues of the tooth and the dental pulp. Refuat Hapeh Vehashinayim 2001;18: 107-108.

42. Wilson M. Photolysis of oral bacteria and its potential use in the treatment of caries and periodontal disease. J Appl Bacteriol 1993;75:299 -306.

43. Moritz A, Jakolitsch S, Goharkhay K et al. Morphologic changes correlating to different sensitivities of Escherichia coli and Enterococcus faecalis to Nd:YAG laser irradiation through dentin. Lasers in Surgery and Medicine 2000;26, 250-261

44. Portenier I, Waltimo T, Ørstavik D, Haapasalo M. The susceptibility of starved, stationary phase, and growing cells of Enterococcus faecalis to endodontic medicaments. J Endod 2005;31, 380-386.

45. Ragot-Roy B, Trainer A, Severin C, Chippaux C. Effect of bactericide in vitro d'un laser Nd:YAG pulse. Journal of Clinical Laser Medicine and Surgery 1994;13, 25-32.

46. Moritz A, Gutknecht N, Goharkhay K, Schoop U, Wernisch J, Sperr W. In vitro irradiation of infected root canals with a diode laser: results of microbiologic, infrared spectrometric and stain penetration examinations. Quintessence Int 1997;28:205-209.

47. Gutknecht N, Franzen R, Schippers M, Lampert F. Bactericidal effect of a 980- $\mathrm{nm}$ diode laser in the root canal wall dentin of bovine teeth. J Clin Laser Med Surg 2004;22: 9-13.
48. De Sauza EB, Cai S, Simionato MR, Lage-Marques JL. High power diode laser in the disinfection in depth of the root canal dentin. Oral Surg Oral Med Oral Pathol Oral Radiol Endod 2008;106:68-72.

49. P. Neelakantan, C. Q. Cheng, R. Mohanraj, P. Sriraman, C. Subbarao \& S. Sharma. Antibiofilm activity of three irrigation protocols activated by ultrasonic, diode laser or Er:YAG laser in vitro. Int Endod J 2015;48, 602-610.

50. R. Ordinola-Zapata, C. M. Bramante, R. M. Aprecio, R. Handysides, D. E. Jaramillo. Biofilm removal by $6 \%$ sodium hypochlorite activated by different irrigation techniques. Int Endod J 2014;47, 659-666.

51. H. Fransson1, K. M. Larsson, E. Wolf. Efficacy of lasers as an adjunct to chemo-mechanical disinfection of infected root canals: a systematic review. Int Endod J 2013;46, 296-307.

52. Omid H. Muhammada, Marlene Chevalier, Jean-Paul Rocca,Nathalie Brulat-Bouchard, Etienne Medioni. Photodynamic therapy versus ultrasonic irrigation: Interaction with endodontic microbial biofilm, an ex vivo study. Photo diagnosis Photodyn Ther. 2014;11:171-181.

53. Brito PRR, Souza LC Machado de Oliveira JC, Alves FR, De-Deus G, Lopes HP, Siqueira JF Jr. Comparison of the effectiveness of three irrigation techniques in reducing intracanal Enterococcus faecalis populations: an in vitro study. J Endod 2009;35:1422-1427.

54. Saber SE, Hashem AAR. Efficacy of different final irrigation activation techniques on smear layer removal. J Endod 2011;37:1272-1275.

55. Gründling GL, Zechin JG, Jardim WM, de Oliveira SD, de Figueiredo JAP. Effect of ultrasonics on Enterococcus faecalis biofilm in a bovine tooth model. J Endod 2011;37:1128-1133.

56. Boutsioukis C, Lambrianidis T, Kastrinakis E, Bekiaroglou P. Measurement of pressure and flow rates during irrigation of a root canal ex vivo with three endodontic needles. Int Endod J 2007;40:504-513.

57. Freitas AI, Vasconcelos C, Vilanova M, Cerca N. Optimization of an automatic counting system for the quantification of Staphylococcus epidermidis cells in biofilms. J Basic Microbiol 2013;54: 750-757.

58. Bergmans L, Moisiadis P, Teughels W, Van Meerbeek B, Quirynen M, Lambrechts P. Bactericidal effect of Nd: YAG laser irradiation on some endodontic pathogens ex vivo. Int Endod J 2006; 39:547-557 